\title{
DISCRIMINACIÓN Y EXCLUSIÓN HACIA MIGRANTES EN EL SISTEMA DE SALUD CHILENO. UNA REVISIÓN SISTEMATIZADA*
}

DISCRIMINATION AND EXCLUSION OF MIGRANTS IN THE CHILEAN HEALTH SYSTEM. A SYSTEMATIC REVIEW

\section{CAROLINA VIVIANA ZEPEDA VEGA 1, M. CRISTINA GONZÁLEZ CAMPOS 2}

\author{
1., 2. UNIVERSIDAD DE ATACAMA, Copiapó, Chile
}

\begin{abstract}
Backgound: The notorious increase of the migrant population towards Chile in the last three decades, raises questions about the need to investigate scientific knowledge about health care. Objective: to demonstrate the situation of migrants in relation to health care. Method: systematic review of the literature in electronic databases: Redalyc, Dialnet and Scielo, with the key words: "and" migrant health; We work with twenty-one articles from 2013 to 2018 , of these sixteen are primary and five secondary studies; ten describe the situation of migrants in Chile; eleven relate the access to the health of migrants from power, perceived discrimination, socio-cultural integration, poverty, public policies, coverage and transnational use of health services. We carry out Content Analysis, based on the categories migration and health, health systems and access to health care. Results: in general, health care is usually experienced amid ignorance, lack of information and discrimination, as barriers to access. Conclusion: the foregoing especially affects the quality of life of the migrant population living in precarious conditions, due to low labor supply and economic resources, violation of rights, discrimination and social exclusion.
\end{abstract}

KEY WORDS: Emigration, immigration, health system, social discrimination, social exclusion.

CÓMO CITAR / HOW TO CITE

Zepeda Vega, C. V., \& González Campos, M. C. (2019). Discriminación y exclusión hacia migrantes en el sistema de salud chileno. Una revisión sistematizada. Salud \& Sociedad, 10(2), 188-204. doi: 10.22199/issn.0718-7475-2019-02-012

\footnotetext{
*Agradecimientos a la Univer sidad de Atacama, Vice-rectoría de Investigación y Postgrado, por beca otorgada a Carolina Viviana Zepeda Vega, para Magister en Metodologías de Investigación Cualitativas en Salud (2018)

1. Magister en Metodologías de Investigación Cualitativas en Salud. Licenciada en Enfermería. Copiapó-Chile. E-mail: carolazepedav@gmail.com • 0RCID: 0000-0002-4299-9313 2. Dra. en Sociología, Antropóloga, A sistente Social, Académica del Depto. De Trabajo Social-Fac. Ciencias Jurídicas y Sociales y del Programa de Magister en Metodologías de Investigación Cualitativas en Salud, Univer sidad de Atacama. Depto. de Trabajo Social, Facultad de Ciencias Jurídicas y Sociales, Univer sidad de Atacama. Copayapu N $485-$ Copiapó - Chile. E-mail: cristina.gonzalez@uda.cl•ORCID: 0000-0002-6225-4490
} 
El incremento de la migración internacional hacia Chile, en las últimas décadas, se hace evidente a partir del censo de 1992. En la actualidad, se estima que habría más de un millón de personas nacidas en el extranjero y que declararon residir en Chile, a partir de resultados del censo de 2017 informados por el Instituto Nacional de Estadísticas (INE). La cifra oficial es de 746.465 personas, provenientes mayoritariamente de Perú $(25,2 \%)$, Colombia $(14,1 \%) \quad$ Venezuela $(11,1 \%)$, Bolivia $(9,9 \%)$. A nivel del país, $1,2 \%$ de los migrantes reside en la Región de Atacama y al considerar la población total de ésta, equivalen al 3,1\% (INE, 2018, p. 9; p.11).

La migración obedece a diversos motivos, predominando el económico. Según estudios previos desde las Ciencias Sociales, tanto cuantitativos como cualitativos, la persona migrante llega al país en busca de nuevas oportunidades laborales y, en consecuencia, mejores condiciones de vida. En el país no existe una política migratoria. Aunque hay iniciativas ministeriales, del Fondo Nacional de Salud (FONASA) y de la Superintendencia del área, destinadas a paliar esta deficiencia, centrándose en el Enfoque de Derechos. Es relevante indagar sobre la migración, en especial si la población de migrantes está en situación de vulnerabilidad y exclusión, de acuerdo a lo planteado por el Departamento de Extranjería y Migración (DEM, 2017) y el Ministerio de Salud (MINSAL, 2017).

Según la Organización Mundial de la Salud (OMS, 2003), la "migración internacional comprende un amplio abanico de movimientos de población, las razones de esos movimientos y la condición jurídica de los migrantes, que determina por cuánto tiempo pueden permanecer en un país de acogida y en qué condiciones" (p. 9). A su vez, la Organización Internacional para las Migraciones define a un migrante como:

cualquier persona que se desplaza o se ha desplazado a través de una frontera internacional o dentro de un país, fuera de su lugar habitual de residencia independientemente de: 1) su situación jurídica; 2) el carácter voluntario o involuntario del desplazamiento; 3) las causas del desplazamiento; 0 4) la duración de su estancia (OIM, 2018, párr. 1).

Uno de los derechos que son vulnerados en la población migrante es el derecho a la salud. La Organización Mundial de la Salud (OMS, 2018) refiere que éste abarca el elemento de accesibilidad, teniendo presente cuatro dimensiones: aceptabilidad, calidad, rendición de cuentas y universalidad. La Atención Primaria en Salud (APS), representa el primer espacio de contacto de los individuos, familia y comunidad con el sistema público de salud, debiendo ser accesible y de costo asequible (OMS, 2018).

En las APS de Chile se distinguen distintos dispositivos administrados a nivel de comunas por los respectivos municipios: Centros de Salud (CES), Centros de Salud Familiar (CESFAM), Centros Comunitarios de Salud Familiar (CECOSF), Postas Salud Rurales (PSR), Servicio de Atención Primaria de Urgencia (SAPU). Considerando que la accesibilidad está a la base del cumplimiento del derecho, es relevante referirse a las barreras $y$ facilitadores. Respecto a las primeras, Cabieses y colaboradores (2017) plantean que: estas impiden el acceso a la atención de salud pudiendo asociarse a la oferta sanitaria y a la demanda; en el primer caso se alude a los costos y organización de los servicios $y$ en el segundo a los conocimientos, creencias, actitudes, entre otros.

En tanto que los facilitadores corresponden a todos los factores que permiten que cualquier persona pueda acceder a los servicios de salud. Destacan los profesionales e integrantes de los 
equipos sanitarios, que acogen a los inmigrantes y los ayudan con distintos mecanismos para que puedan acceder sin problemas a la atención; compartir el mismo idioma actúa en el mismo sentido. Considerando lo expuesto, esta revisión sistematizada busca evidenciar la situación de las personas migrantes respecto a la atención en salud.

\section{MÉTODO}

A continuación, presentamos los siguientes aspectos: estrategia de selección de artículos, criterios de inclusión, estrategia de análisis y procedimiento para desarrollar las categorías.

\section{Estrategia de selección de artículos}

La búsqueda fue efectuada en las bases de datos electrónicas: Redalyc, Dialnet y Scielo. Utilizamos como palabras claves salud y migrantes y limitando la búsqueda al periodo comprendido en los últimos cinco años, a partir de 2013. Al momento de realizar la búsqueda, el resultado fue mayoritariamente artículos en español, alcanzando una totalidad de 171,506 artículos, correspondientes 171,284 a la base Redalyc, 210 a Dialnet y 7 a Scielo. Además, incluye otras cinco publicaciones no derivadas de la búsqueda en las bases, pero reportadas por el sistema, indexadas en Latindex, World Of Science-Scopus.

Las publicaciones seleccionadas fueron filtradas, en primera instancia, por año (2013 a 2018), idioma (español e inglés), disciplina (Salud y Ciencias Sociales), permitiendo acotar el corpus de 171.506 a 307 artículos. En segunda instancia, la selección fue en forma manual, revisando la pertinencia en títulos y resúmenes, obteniendo 41 . Al eliminar los duplicados, trabajé con un total de 21, que cumplen con los siguientes criterios de inclusión

- Tipos de estudios: primarios y secundarios.
- Métodos de investigación: cualitativos y cuantitativos.

- Perfil de muestra: migrantes latinoamericanos, con independencia de su situación migratoria.

- Temporal: estudios publicados entre 2013 y 2018.

- Geográfico: países americanos y europeos.

- Idiomático: estudios originales publicados en inglés y español.

- Área de conocimiento: estudios desde las ciencias sociales y de salud.

\section{Estrategia de análisis}

Realizamos un análisis de contenido aplicado (Bardin, 1996), con el apoyo del programa computarizado NVivo 11 Pro, específicamente en la codificación del material.

\section{Procedimiento para desarrollar las categorías}

El análisis se centra en el contenido explícito, según planteado por Hernández, Fernández, Baptista (2014), aplicando una estructura de interpretación en base a categorías y subcategorías, para describir los elementos comunes presentados por los autores. Para ello hemos aplicado categorías a priori y a posteriori. En el primer caso, migración, se traduce en las subcategorías a posteriori: concepto de migrante, condiciones en el país receptor, integración socio - cultural de los migrantes, y experiencias de discriminación y exclusión hacia los migrantes. En el segundo, salud, sistemas de salud y acceso a la atención de salud, se ubican las subcategorías: determinantes sociales de salud, experiencia de los migrantes en el área de salud y en el acceso al sistema de salud y contrapoder/hegemonía en el proceso de atención de salud de los migrantes.

\section{RESULTADOS}

Las categorías iniciales de análisis, de acuerdo al planteamiento de objetivos, 
resultaron ser: migración y salud, sistemas de salud y acceso a la atención de salud, identificándose a la vez siete subcategorías. El análisis de éstas será presentado a continuación.

\section{Migración}

Esta categoría permite, en primera instancia, desglosar el concepto de migrante, desde los artículos revisados. Asimismo, se abordan las condiciones presentes en el país receptor, para referirse luego a la integración socio-cultural. En último término se destaca lo referido a experiencias de discriminación y exclusión que enfrentan algunos segmentos de migrantes en las sociedades receptoras.

\section{Concepto de migrante}

En general, los autores (Abeldaño, 2016; Cabieses et al., 2017; De la Flor, 2013; Frías, Galaz y Poblete, 2017; Rocha, Darsie, Gama \& Días, 2014; Santos, Limón \& Martínez, 2016; Stefoni \& Bonhomme, 2014) adhieren y citan la definición propuesta por la Organización de la Salud (OMS, 2003): "el concepto de migrante se refiere a las personas que abandonaron su país de origen por razones económicas, sociales, ambientales o políticas en el sentido de mejorar sus condiciones de vida".

En tanto que otros (González-Vásquez, Torres-Robles \& Pelcastre-Villafuerte, 2013; Torres \& Garcés, 2013; Trummer, Simonnot \& Vanbiervliet, 2016) se refieren a la definición de la Organización Internacional para las Migraciones (OIM, 2018, párr.1) que define a un migrante como "cualquier persona que se desplaza o se ha desplazado a través de una frontera internacional 0 dentro de un país, fuera de su lugar habitual de residencia". Al respecto, se considera que esta acepción hace referencia al desplazamiento y no necesariamente al cambio de residencia habitual.

Mientras que Lahoz y Forns (2016), al enfatizar la salida del lugar de origen y asociarla con la búsqueda de trabajo, limitan el alcance del término al centrarse en una de las primeras fases del proceso, excluyendo la posibilidad de pronto retorno y a la vez se focalizan en lo laboral, descuidando otros motivos a la base. Otro concepto asociado resulta ser el de circulación migratoria, indicado para referirse a migrantes que se desplazan a otro lugar de manera transitoria, repetitiva o cíclica, sin la intención de una residencia permanente 0 de largo plazo (Cortés, 2009).

En la actualidad, esto implica reconocer la migración a nivel internacional, ya que es necesario tener presente que ha aumentado a nivel mundial, activándose tensiones entre el poder establecido, determinados sectores de las sociedades receptoras y quienes migran, en especial si estos últimos ingresan en condiciones muy adversas al país de destino, se encuentran en situación de irregularidad administrativa o los flujos se incrementan de forma evidente y rápida, entre otros factores. Ello activa la percepción de que algunos colectivos están excesivamente representados, incidiendo en que desde la población nativa se generen y mantengan estereotipos que inciden de forma negativa en la aceptación social de los otros, a quienes se diferencia respecto de nosotros.

\section{Condiciones en el país receptor}

En los artículos seleccionados predominan aquellos centrados en Chile como país de destino (Baby-Collin \& Cortés; 2014; Cabieses et al., 2017; Frías, Galaz \& Poblete, 2017; Lahoz y Forns, 2016; Liberona, 2015; Pavez, 2017; Stefoni \& Bonhomme, 2014; Torres \& Garcés, 2013), aunque también se incluyen algunos con otros destinos migratorios, como: Argentina, Estados Unidos de América, México, España y Portugal (Abeldaño, 2016; Carrasco, 2018; De la Flor, 2013; González-Vásquez et al., 2013; Hernández, 2013; Monge \& PérezMolina, 2016; Rocha et al., 2014; Santos et al., 2016; Trummer et al., 2016). 
La migración internacional reciente hacia Chile comenzó a evidenciarse desde la última década del siglo $\mathrm{XX}$, destacando el flujo proveniente en un primer momento de países vecinos de América del Sur, para luego extenderse a Centroamérica. Según los datos censales (INE, 2017), los principales países de origen son: Perú $(25,2 \%)$, Colombia $(14,1 \%)$, Venezuela $(11,1 \%)$, Bolivia $(9,9 \%)$, Argentina $(8,9 \%)$, Haití $(8,4 \%)$ y Ecuador $(3,7 \%)$.

Los movimientos migratorios actuales se asocian al trasnacionalismo, considerado como una migración definitiva o transitoria, que construyen una trayectoria en el país receptor (Frías et al., 2017; Liberona, 2015; Stefoni \& Bonhomme, 2014). Cabe destacar que, según la OIM (2010), implica "estar conectado con varios lugares a la vez -o no estar ni aquí ni allá- (...). Llevar vidas transnacionales, en sitios múltiples". Esto es relevante, porque los migrantes no se establecen en forma definitiva en un lugar, ya que es habitual el tránsito entre el país de origen y el receptor, en distintos momentos y al alero de nuevas oportunidades laborales 0 económicas.

Por otro lado, resulta interesante señalar que las personas que migran a Chile, en su mayoría viven en grandes centros urbanos como, por ejemplo, Arica, Antofagasta, Valparaíso y Santiago (Frías et al., 2017). El impacto que conlleva la migración en el país receptor, puede verificarse a nivel demográfico, socioeconómico, laboral, legislativo y cultural, y constituir un factor sobresaliente para el desarrollo económico del país receptor, en la medida que representa un aumento considerable de mano de obra disponible para diversas actividades y sectores profesionales (Rocha et al., 2014).

Una característica de las culturas particulares es precisamente su diversidad, por eso es importante reconocer el contexto en que se desarrolla la migración. Es necesario tener en cuenta la migración internacional, que representa un desafío para los países que pasan a constituirse como puntos de destino, por la complejidad que ello supone, en especial si sobrevienen crisis que inciden en la elección de los lugares hacia donde se dirigen los flujos. Por ejemplo, España fue destino migratorio preferente, hasta que se evidencia crisis en su economía; a partir de ello, las personas originarias de Bolivia prefieren migrar hacia Brasil y Chile (Baby-Collin et al., 2014).

Por tanto, se reconoce la migración internacional como un proceso que involucra no sólo al país de origen y al o los de destino, sino también los de tránsito y retorno (Rocha et al., 2017). El aumento de la migración ocurre también hacia otros continentes, como por ejemplo a Europa, que se enfrenta hoy en día a un mayor aumento de flujo de migrantes no regulares. Según informa la OIM (2015), "hay más de un millón de migrantes irregulares que llegaron a Europa en 2015, en su mayoría procedentes de Siria, África y Asia meridional". Por consiguiente, han tenido que coordinar políticas migratorias países como Suecia, Portugal, Nueva Zelanda, Noruega y Bélgica, que llaman a la residencia y nacionalidad permanente de los migrantes, para promover su participación activa y la integración a nivel política, educacional, en salud, entre otros (Carrasco, 2018; Trummer et al., 2016).

Es necesario que se regularicen las normativas y políticas migratorias del país, ya que, de acuerdo a las tendencias observadas, el incremento de las cifras es altamente probable a nivel global y es preciso que haya regulaciones estandarizadas para todos los países que quieran recibir a migrantes, de modo que, si una persona migra hacia cualquier país, enfrente más 0 menos las mismas condiciones $y$ regulaciones que si fuese a otro. A la vez, si se asume que la migración es un derecho, entonces no se sustentan requisitos diferenciales para las personas provenientes de distintos países, pues desde la base, ello se configura en los hechos como una práctica discriminatoria. 
Es importante reconocer el contexto socio-cultural de las personas que migran al país, y sobre todo en el ámbito de salud, puesto que es necesario que los equipos se aproximen a la cultura de la población migrante situada en su población asignada, en pos de una mejor atención. A nivel de los países receptores esto representa un desafío, debido a la complejidad que supone una diversidad creciente, sumado a la ausencia de políticas de integración y a la falta de actualización de la ley respectiva que regula la materia.

\section{Integración socio-cultural de los migrantes}

El concepto de integración es complejo, ya que ineludiblemente refiere a los modelos sociales y culturales dominantes en un territorio (Pavez, 2017). Según Solé y colaboradores (2011), "el concepto de integración considera tanto las diferencias culturales de las personas y los grupos migrantes, así como las condiciones sociales, económicas y políticas en las cuales vive" (p. 63). Este proceso está relacionado con la adaptación recíproca, que desarrollen tanto quienes migran, como la sociedad receptora.

Sin embargo, en general suele expresarse una tendencia asimilacionista, en que predomina la cultura de esta última, desconociendo la cultura de los migrantes. En este sentido, Lahoz y Forns (2016), Pávez (2017) y Rocha et al. (2014) enfatizan que el contacto se da en contextos de discriminación. Tanto Liberona (2015), De la Flor (2013) como Frías et al. (2017) coinciden en relacionarlo con exclusión social; adicionalmente, Carrasco (2018), Cabieses et al. (2017) y Frías et al. (2017) destacan que el proceso está marcado por la pobreza y carencias económicas, de modo que los migrantes se sienten excluidos, víctimas de la desigualdad social.

Para las personas migrantes adultas, tomar la decisión de salir de su país para instalarse en otro resulta una tarea difícil, porque su proceso de adaptación implica no sólo llegar a conocer una nueva cultura y una nueva realidad, sino que también saber cuáles son sus derechos y estar en condiciones de defenderlos. Sin embargo, ello se dificulta en la medida que tiende a predominar la desinformación al respecto, de modo que el desconocimiento incrementa el riesgo de ser expuestos a condiciones de vulneración y explotación, por ejemplo, en lo laboral.

A nivel de integración, se concuerda con Pavez (2017), respecto a que la sociedad y sus modelos, políticas y estructuras influyen positiva o negativamente en la integración, en el entendido que incluso no toda la población foránea es igualmente aceptada por la sociedad, viviendo procesos de exclusión. Esta situación puede afectar con mayor intensidad a determinados grupos 0 colectivos migrantes, bajo la forma de exclusión diferencial asociada a rasgos físicos, culturales, de género, situación económica, entre otros.

Como lo expresan Levitt y Glick (2004), la experiencia de vida de los migrantes nos dice que más que sectores excluyentes y situados en forma definitiva en uno u otro lugar, las situaciones diversas que presenta la migración, cobran más sentido si se desarrollan vivencias complementarias y se construye en conjunto la realidad cotidiana.

\section{Experiencias de discriminación y exclusión hacia los migrantes}

En cuanto a las experiencias de discriminación y exclusión percibidas por los migrantes, Lahoz y Forns (2016), plantean que "la mayoría de los y las migrantes afirman haber sufrido algún tipo de discriminación personal por parte de la población chilena" (p. 160), a la vez, destacan que "las y los peruanos migrantes perciben mayor discriminación dirigida a su grupo como un todo que a ellos, personalmente" (p. 63). Así mismo, Rocha et al. (2014) señalan que los migrantes tienden a ser foco de actitudes discriminatorias en los países de acogida. En base a lo expuesto, 
las personas migrantes en mayor o menor medida son discriminadas por la simple condición de ser extranjeras en el país receptor, provocando cierta segregación en distintos ámbitos.

Esta exclusión es percibida como determinante de desigualdad por quienes han migrado; surgen nuevos desequilibrios y desigualdades que superan la barrera socioeconómica y podrían inducir la marginación. según Frías et al. (2017, p.73) "el concepto de exclusión social sirve para visualizar aquellas situaciones que, más allá de la privación económica, se sufre una privación de la propia idea de ciudadanía, 0 , dicho de otra manera, de los derechos y libertades (Subirats, 2010)".

Las desigualdades sociales se vinculan a la inclusión/exclusión, por ejemplo, en función de edad, sexo, etnia, religión, procedencia nacional, entre otros aspectos; en el caso de las personas migrantes con su situación administrativa regularizada o no, puede sumarse una precaria situación económica, de modo que pueden constituirse como uno de los sectores sociales más susceptibles de sufrir algún grado de exclusión (Frías et al., 2017).

Algunos autores, entre ellos Cabieses et al. (2017) y Carrasco (2018), relacionan la exclusión social con indicadores de pobreza, por el desempleo que podrían experimentar especialmente en los primeros meses de arribo al país de acogida. Así, el término exclusión normalmente se relaciona con indicadores de pobreza, de carencia económica, y privaciones materiales. Además, la exclusión se ve aumentada en la medida que algunos segmentos de la población nativa rechacen o prefieran la salida de los migrantes (De la Flor, 2013).

De modo que, las personas que migran pueden ser víctimas de discriminación y exclusión social, estando el riesgo de que sean vulnerados sus derechos; esta situación suele ser justificada por determinados sectores de la población nativa, apelando a motivos económicos, etno-raciales, entre otros, utilizados como argumentos para adherir a tendencias expulsivas. En este contexto, la presencia de estereotipos negativos habitualmente está vinculada a las imágenes que se sostienen desde los medios de comunicación (Cea. Valles \& Eseverri, 2013; Cogo, Gutiérrez y Huertas, 2008; Hopenhayn \& Bello, 2001).

De acuerdo al objetivo de esta revisión, interesa destacar lo que acontece en los centros de salud pública. Así, en el estudio de Liberona (2015) se hace referencia a la discriminación hacia las personas migrantes al acudir a los Centros de Salud, aspecto que será desarrollado en la siguiente categoría.

Salud, sistemas de salud y acceso a la atención de salud

La segunda categoría se relaciona con la salud y el acceso a ésta. Es necesario tener presente que la salud está determinada socialmente y no sólo desde lo biológico. En general, la población requiere ser atendida y no siempre se dan las condiciones óptimas para asegurar el cumplimiento de este derecho, situación que afecta en mayor medida a un segmento de quienes migran, precisamente a aquellos que viven en condiciones más precarias. Por ello, se aborda la experiencia de los migrantes en este ámbito, focalizando en el acceso al sistema sanitario; las dificultades que enfrentan les llevan a desarrollar el contrapoder, como mecanismo de respuesta.

\section{Determinantes sociales de la salud.}

La OMS establece que "los determinantes sociales de la salud son las circunstancias en que las personas nacen, crecen, viven, trabajan y envejecen, incluido el sistema de salud" (2004, párr. 1).

Para entender el proceso al cual están enfrentadas las personas migrantes y la situación de vulnerabilidad a la que están expuestos, cabe considerar lo planteado por Abeldaño (2016), Carrasco (2018), Cabieses 
et al. (2017), Frías et al. (2017), Rocha et al. (2014) y Trummer et al., (2016), que abordan la relación entre acceso y determinantes sociales de la salud. Lo anterior se expresa en el caso de las personas migrantes respecto de las instituciones de salud pública y/o privada. A su vez, Cabieses et al. (2017), Torres y Garcés (2013) mencionan que existen facilitadores y obstaculizadores para el acceso, transformándose respectivamente en experiencias positivas 0 negativas para los migrantes.

Según el Ministerio de Salud (MINSAL, 2015), las determinantes sociales de salud se entienden, como "las condiciones sociales en que las personas viven y trabajan, que impactan sobre la salud" (s.p), además hace mención a que son objeto de políticas públicas modificables mediante intervenciones. Este concepto ha aparecido hace dos décadas debido a la interrogante respecto a si la salud debe ser una responsabilidad social o sólo corresponde al plano individual. En la actualidad, Portugal cuenta con políticas públicas de inclusión y lucha contra la pobreza, ya que el contexto de pobreza y exclusión social aumenta los riesgos de afección en la salud (Rocha et al. 2014).

En Chile, los dos determinantes anteriores repercuten directamente en condiciones sanitarias deficientes y por lo tanto inciden en un empeoramiento del estado de salud, debido al bajo ingreso económico que tiene un segmento de las familias migrantes; al poco acceso a los servicios disponibles; a los costos asociados; y a la insatisfacción que pueden tener las personas, debido a las experiencias negativas relacionadas con problemas de acceso a la atención de salud (Cabieses et al., 2017).

Hay que considerar la relación entre migración, desigualdad social y salud (Santos et al., 2016). Una persona puede tener una mejor cobertura de salud si cuenta con las condiciones económicas necesarias y tiene la posibilidad de libre elección. Al respecto se puede plantear que quienes migran suelen enfrentar mejora en las condiciones laborales y salariales en la medida que su situación se estabiliza y tienen más tiempo de permanencia; en tanto que, si la experiencia migratoria se transforma en mayores pérdidas que ganancias, probablemente el proyecto se modifique, activando la posibilidad de retorno o de migración hacia otro punto de destino.

En general, se estima que en las etapas iniciales cierta proporción puede estar en condiciones de precariedad económica, por falta de trabajo o baja remuneración; a la vez, no siempre tendrá cobertura de salud, sea porque su empleador no hace efectivo el pago de las cotizaciones previsionales de salud, porque se encuentran en situación irregular 0 por desconocimiento de sus derechos.

Es preciso plantear que en los hechos se produce cierta discriminación, puesto que para acceder a los establecimientos de salud del sistema público se requiere la calificación previsional, en la que se clasifica en primera instancia a los nacionales y extranjeros, y a éstos últimos por su situación de regulares 0 irregulares (Pavez, 2017). Esto implica que se pone en evidencia a las personas migrantes que se encuentran en esta última condición, dejando abierta la posibilidad de distancia en la atención, además, de esta forma se logra diferenciar entre las personas que tienen previsión y las que no, activando la discriminación institucional.

Por tanto, en el ámbito de la salud pública es necesario comprender cómo es el acceso, tener en cuenta el proceso migratorio por el que atraviesan, ya que se visualiza que hay experiencias de discriminación y de exclusión, ligadas a estratos sociales diferenciados y a la segmentación social presente en el país. En este sentido, cabe tener presente que en el sistema de salud se incluyen todas las organizaciones, instituciones y recursos orientados a mejorar 
la salud, debiendo responder de manera equitativa a las necesidades de la población especialmente considerando que puede contribuir a la reducción de la pobreza y al fomento del desarrollo (OMS, 2005).

Pese a lo anterior, en el periodo de la dictadura militar en Chile, específicamente a comienzos de los años ' 80 y bajo la marca de una lógica de mercado, se establecieron cambios significativos en el sistema, pasando a constituirse una red de salud mixta, compuesta por entidades públicas y privadas. Ello supone el traspaso de parte de la administración y la APS a los municipios, constituyendo la vertiente pública; en tanto que las Instituciones de Salud Previsional (ISAPRES) son la base del sistema privado. De este modo, la población es segmentada, pues accede a uno u otro; adicionalmente, cabe señalar que la libre elección permite a todos los usuarios decidir dónde recibir las prestaciones, pues ambos sistemas no son mutuamente excluyentes en el otorgamiento de éstas.

Quienes tienen más ingresos tienden a optar por el sistema privado, aunque también está la posibilidad de que adhieran libre y solidariamente al público; a su vez, las personas y familias de menores ingresos 0 que carecen de ellos, se constituyen en la mayoría de los beneficiarios del sistema público. Al respecto, cabe destacar lo planteado por Cabieses y colaboradores (2017), en el sentido que la pobreza y la salud son dos conceptos que están estrechamente relacionados y donde la salud auto-percibida se ve mayormente afectada si las experiencias de acceso resultan negativas, por dificultades 0 barreras. Lo anterior se asocia a la posición socioeconómica, pues quienes cuenten con más recursos económicos o deciden utilizar las prestaciones que ésta entrega, tienen la posibilidad de acceder a la salud privada 0 pública.
Experiencia de los migrantes en el área de salud y en el acceso al sistema de salud.

Al referirse a la situación en Estados Unidos de Norte América, González-Vásquez y colaboradores (2013), plantean dificultades en el acceso a la salud en migrantes mexicanos que permanecen de manera irregular en el país. Destacan el desconocimiento acerca de los servicios, el idioma, la cultura, el miedo y la desconfianza, esto, junto con algunas características del sistema de salud mexicano como el bajo costo de la atención, el acceso a medicamentos sin receta, entre otros. Todo lo anterior motiva el uso de atención sanitaria de forma transnacional, mediante consultas telefónicas 0 a través de familiares residentes en México. Por otra parte, los migrantes documentados con seguro de salud, tienen mayor acceso a los sistemas formales de atención tanto en EUA como en México. En contraposición, los migrantes documentados sin seguro de salud, evitan pagar los altos costos en la atención en EUA, y recurren a médicos clandestinos.

Los estudios de Abeldaño (2016), Carrasco (2018), Frías y colaboradores, (2017) y Pavez (2017) se relacionan con las experiencias que tienen los migrantes en salud, por la vulnerabilidad en que se encuentran quienes no tienen cobertura sanitaria, en especial en los primeros meses o años posteriores a su llegada. Asimismo, Rocha y colaboradores. (2014) y De la Flor (2013), coinciden en plantear que los migrantes son grupos socialmente vulnerables, sólo por el hecho de haber salido de su país y cruzado la/s frontera/s.

Por otro lado, tanto Cabieses (2017) como Torres y Garcés (2013) se refieren a experiencias positivas y negativas de quienes migran, al existir barreras y facilitadores en el acceso a la salud, y hacen hincapié en las barreras administrativas que se presentan en el Servicio de Orientación Médico Estadístico (SOME), hacia las personas migrantes. 
Frías y colaboradores (2017) mencionan el desconocimiento respecto al derecho a la atención; mientras que Abeldaño (2016), se refiere a los recursos disponibles y a la baja capacidad que tiene el Estado de responder a las necesidades de las personas migrantes en el contexto nacional. En Chile, la mayoría de las personas migrantes accede a las prestaciones de salud a través del sistema público o FONASA, aunque también a la atención privada, que lideran las ISAPRES.

Pese a lo anterior, hay que tener presente que existe un segmento que se autoexcluye y no accede a ningún tipo de prestación de salud, preferentemente por su condición de estancia irregular en el país, por la realización de trabajos informales, entre otros motivos. Es importante para la salud pública, ya que quienes migran pueden llegar a estar en una situación de mayor vulnerabilidad, al no tener cobertura sanitaria que garantice el derecho a la salud (Frías et al., 2017; Pavez, 2017). Además, como refieren Frías y colaboradores "existe un sector de la población migrante que no accede a ningún tipo de prestación de salud, un $8,9 \%$ de esta población, sin considerar la población irregular" (2017, p.71).

Es por esto que es relevante y motivo de preocupación que haya migrantes sin cobertura sanitaria, puesto que su situación de vulnerabilidad se acrecienta y complejiza. La población migrante, al cruzar la frontera incrementa la exposición al riesgo y socialmente se hace vulnerable, debido a su condición de extranjeros, a las pocas capacidades de hacer valer sus derechos, a no contar con la información o herramientas necesarias, como las redes de apoyo, recursos económicos, entre otros, para lograr enfrentar el proceso migratorio de forma que garantice el logro de las expectativas previas al desplazamiento (Abeldaño, 2016; Carrasco, 2018; Rocha et al., 2014; De la Flor, 2013).

Entre las prestaciones de salud que brinda el Estado chileno, es preciso destacar al AUGE/GES (Garantías Explícitas en Salud), que corresponde a un beneficio legal destinado a usuarios de sistema público y privado, ya que son garantías relacionadas con acceso, calidad, protección financiera y oportunidad, las que se conjugan en programas que incluyen un total de ochenta patologías (Superintendencia de Salud, sf). En esta línea, en el estudio de Cabieses et al. (2017), respecto a los migrantes se señala que "existe un $23,1 \%$ de la población migrante que no se encontraba cubierto por el AUGE/GES en comparación con $14,2 \%$ en chilenos" (p. 46). Datos relevantes, ya que los migrantes también tienen derecho de recibir estas prestaciones, dispuestas no sólo para la población chilena.

El sistema de salud y sus representaciones sociales puede incidir en dos dimensiones, la primera corresponde al acceso, realizando diferencia entre sistema privado y el público. En el primero, las personas pueden acceder siempre y cuando tengan regularizada la situación laboral y se efectúe el pago de las cotizaciones. En el segundo, o público, se incluyen experiencias que pueden ser directas; llamadas individuales de atención; que pueden ser positivas 0 negativas y no generalizables, como pueden ser las narradas por conocidos y que pueden tener ejes de dificultades 0 facilitadores brindadas a los migrantes y las habilidades que éstos pueden desarrollar ante el rechazo por no recibir atención. La segunda dimensión se refiere a la calidad de la atención, donde se hace referencia al respeto que la persona migrante debe recibir y dar, como, por ejemplo, evitar o reducir los tiempos de acceso a consulta y de espera en la atención, abuso, engaño, malos tratos, entre otros (Torres \& Garcés, 2013).

En el contexto nacional hay obstaculizadores en el acceso a la atención de salud de las personas migrantes, entre los que se distinguen barreras administrativas y legales, además el temor a la deportación de la población migrante en situación de permanencia irregular en el país, limita su 
asistencia al sistema sanitario. Entre las barreras administrativas se encuentran el conflicto interétnico, observado, por ejemplo, en el caso de una funcionaria de SOME que asegura que los migrantes son personas difíciles, exigentes y poli-consultantes (Liberona, 2015).

Pero no debieran tener esa percepción de los migrantes puesto que, es el primer lugar donde uno debe ir cuando ingresa a una institución pública de salud, y donde deberían responder a las solicitudes e inquietudes de todos los pacientes, brindarles la hora o explicarles por qué no pueden dársela y no obstaculizar la gestión, sólo porque les falte algún documento. Estas situaciones pueden desencadenar enojo, incomprensión y reacciones a la luz de un espacio público de salud, relevando la importancia de la política pública (Liberona, 2015; Pavez, 2017).

Dentro de las barreras legales, la principal dificultad con que se encuentra la población migrante en Chile es la documentación exigida para residir en el país de forma legal y el marco restrictivo que tiene la actual Ley de Extranjería (Decreto Ley 1094 de 1975), generando una población flotante de personas en situación irregular, que no puede acceder a la oferta de salud del país. En cuanto a programas para migrantes, por un lado, se han implementado las medidas tomadas en el área de salud, a partir principalmente del Programa de Acceso a la Atención de Salud a Personas Migrantes, aprobado en el año 2014. Por otro lado, a nivel ministerial, se estableció un equipo sectorial asesor de Salud de Migrantes, que cuenta con representación de la Subsecretaría de Salud Pública, Subsecretaria de Redes Asistenciales, FONASA y la Superintendencia de Salud, para estos fines también se han desarrollado un acumulado de decretos y normativas acerca de la atención a la población migrante.
En el caso de migrantes regulares y que cotizan en el sistema sanitario, la condición de accesibilidad a los servicios de salud no presenta mayores dificultades. En cambio, los migrantes irregulares sólo tienen derecho a la atención gratuita en los servicios de urgencia de la red asistencial; las niñas, niños y adolescentes menores de 18 años y las mujeres embarazadas tienen derecho a ser atendidos en los establecimientos de APS, aunque existe un desconocimiento por parte de las personas migrantes de cuáles son los programas a los que pueden acceder embarazadas y menores de 18 años, con independencia de su situación migratoria en términos de estancia regular o irregular en el país (Frías et al., 2017).

Para Cabieses (2017), el problema con el acceso a la salud chilena, se relaciona más bien con los recursos disponibles para la población migrante y la capacidad que tiene el sistema de responder a sus necesidades. La cobertura de salud es importante, ya que la adscripción al seguro de salud puede repercutir directamente sobre la diferenciación entre nativos/migrantes.

Por lo tanto, en el contexto nacional se presentan obstaculizadores en el acceso a la atención de salud de las personas migrantes, manifestándose en barreras administrativas y legales a la atención. Además, el temor a la deportación de la población migrante en situación de estancia irregular en el país limita su asistencia a establecimientos de la red de salud.

Por otra parte, existen facilitadores en el acceso, observados por ejemplo en el caso expuesto por Liberona (2015), sobre una nutricionista que relató que en los primeros años de la llegada de pacientes migrantes al sistema, una de las cosas que provocaba la incomprensión de sus colegas era la forma de alimentación, específicamente de los migrantes peruanos, y por ende, se generaban malos tratos y poca resolución terapéutica, por esta razón es que la misma nutricionista conoció la comida peruana y sus 
componentes nutritivos, que a diferencia de la comida chilena, era más rica en proteínas. Se ve claramente la intención de la profesional por querer ayudar a las personas migrantes, buscando acercarse al conocimiento de su cultura y así mejorar la calidad de su atención. Por esto, la relación que puede llegar a establecerse, la confianza $y$ el interés que demuestran algunos profesionales de entender, incluso el idioma y creencias culturales, facilitan el acceso de las y los migrantes al sistema oficial de salud del país, aunque queda supeditada a la voluntad y buena disposición de quienes integran el equipo de salud, sea guiados por el interés respecto a la cultura de otra persona, porque han tenido la experiencia de conocer situaciones de migración u otros motivos o circunstancias que les hacen más sensibles al tema y a la búsqueda de mejoras en la atención.

Una salida alternativa emprendida por algunos profesionales de la salud consiste en el desarrollo de mecanismos informales para la atención de las personas migrantes no regulares 0 para las personas que están situados en los estratos socioeconómicamente más desfavorecidos, para facilitar el acceso, por ejemplo, mediante la asignación de un número de cédula que posibilita el ingreso del caso al sistema o la clasificación en categoría de indigencia, para no hacer efectivos los cobros asociados a las prestaciones.

Otra iniciativa proviene de entidades de la sociedad civil, como consulados y oficinas de inmigración que actúan como agencias mediadoras, ayudando a través de la entrega de información, acompañamiento e incluso pagos directos por prestaciones en casos de mayor complejidad y vulnerabilidad socioeconómica (Frías et al., 2017).

Por tanto, algunos de los facilitadores para el acceso a la atención de salud en Chile se derivan de los profesionales de la salud y de entidades de la sociedad civil, consulados y oficinas de inmigración, que actúan en paralelo y en respuesta a la ausencia de una política pública instituida desde el Estado. Finalmente, cabe destacar que la existencia de barreras sustenta la necesidad de crear políticas públicas para regularizar las situaciones que se dan en la atención pública de salud en Chile, enfatizada por Liberona (2015) y Pavez (2017).

Contrapoder/ hegemonía en el proceso de atención de salud de los migrantes.

Liberona (2015) y Torres y colaboradores (2013) coinciden en plantear la hegemonía que existe en el sistema de salud chileno, y las respuestas generadas por algunos colectivos migrantes, para ser atendidos en los centros de salud. Se genera así el contrapoder, referido a la capacidad de respuesta de parte de las personas subalternas, destinada a revertir el poder que las personas dominantes pueden tener sobre ellas (Márquez-Fernández \& Díaz, 2005).

Esto cobra importancia y se atribuye en este caso a la relación de poder que puede establecerse entre los funcionarios de salud y la población migrante, influyendo en diversos conflictos en el contexto de la atención de salud, por ejemplo, dilatar el tiempo de espera para la atención, asignación preferente de horas a personas nativas, entre otras (Liberona, 2015).

Llama la atención, que se haga referencia al contrapoder desarrollado por migrantes peruanos (Liberona, 2015), para acceder a la atención en salud, siendo más directos que la población chilena en sus requerimientos y exigiendo su derecho a la atención. A pesar de que existe poder dentro de los establecimientos de salud por parte de las 0 los funcionarios, mantienen posturas $y$ actitudes diferentes a la población chilena, siendo más directos en sus requerimientos. En el mismo sentido, Torres y colaboradores, (2013) refieren, que: "las migrantes usuarias del sistema de salud también entienden que deben desarrollar sus propias estrategias de acceso a la atención cuando ésta se ve obstruida o se complica" (p. 320). 


\section{CONCLUSIÓN}

La migración es un proceso dinámico; uno de sus rasgos en las últimas décadas es el transnacionalismo, expresado en la tendencia a estar simultáneamente acá y allá. Pese a existir distintos motivos que sustentan el proceso migratorio, tiende a predominar la búsqueda de mejores oportunidades y lo económico suele estar a la base.

La situación de quienes migran hacia otro país es diversa, algunos sectores podrán acceder a bienes y servicios en condiciones similares e incluso superiores a las de algunos segmentos de la sociedad receptora, en tanto que otros vivirán en condiciones de privación, discriminación y exclusión.

Interesa destacar la situación de quienes viven en condiciones más precarias, probablemente en situación de irregularidad administrativa, debido a su ingreso al país por algún paso no autorizado o bien, por no haber renovado su documentación una vez vencido el período de estancia legal. A ello se suma quienes estando con su situación administrativa regular, se ven expuestos a vulneración de derechos, en distintos ámbitos, donde lo laboral tiende a incidir directamente en los ingresos, satisfacción de necesidades $y$, por ende, en la calidad de vida.

Uno de los aspectos que influye fuertemente en la calidad de vida es la salud $y$ en ese sentido, interesa destacar la experiencia de las personas migrantes, especialmente a nivel del sistema público, al que accede la mayoría. La experiencia en el sistema de salud pública, tanto de quienes se encuentran en condiciones de estancia regular o irregular, suele estar marcada por la marginación, discriminación y exclusión social. Su calidad de vida se ve deplorada por falta de recursos y precariedad laboral, aspectos que se constituyen en los principales determinantes en el acceso a la atención de salud; encontrándose sumergidos en las experiencias positivas y negativas, al asociarse a barreras $y$ facilitadores existentes en el sistema de salud, especialmente en el sistema público.

Finalmente, cabe destacar que esta revisión sistematizada deja abierta la temática para ser abordada a posterioridad, por ejemplo, buscando comprender cómo se expresa y es vivenciada la discriminación y exclusión en la salud pública, desde la perspectiva de distintos sectores, por ejemplo, de adultos mayores, mujeres, niños y niñas, adolescentes.

Lo anterior con el propósito de aportar insumos que podrían contribuir a la elaboración de una política pública o de estrategias intersectoriales que permitan hacer frente a la vulneración de derechos 0 a la toma de conciencia respecto a cómo socialmente se asume la diversidad, teniendo presente la necesidad de inclusión en la vida cotidiana, de respeto mutuo a las diferencias.

\section{REFERENCIAS}

Abeldaño, A. (2016). Cobertura de seguro de salud de los migrantes residentes en la ciudad de Salta, Argentina. Revista Chilena Salud Pública, 20(1), 53-56. Recuperado de: https://revistasaludpublica.uchile.cl/inde x.php/RCSP/article/download/39337/40 958/

Baby-Collin, V. y Cortes, G. (2014). Nuevos despliegues del campo migratorio boliviano frente a la crisis. Revista CIDOB d'Afers Internacionals, 106-107, 61-83. Recuperado de https://halshs.archivesouvertes.fr/halshs-01270111/document Bardin, L. (1996). Análisis de Contenido. Madrid, España: Akal Ediciones

Cabieses, B.; Pedrero, V.; Oyarte, M.; Sirlopu, D.; Alfaro, J., Bernales, M. y Flaño, J. (2017). Pobreza Multidimensional, Salud Auto-Percibida y Acceso a Salud en Chile: Generando 
Conocimiento Crítico para la Acción en Red en Salud Pública. Santiago de Chile: Universidad del Desarrollo. Recuperado de: http://repositorio.udd.cl/bitstream/handl e/11447/1633/Pobreza\%20multidimens ional $\% 2 \mathrm{C} \% 20$ salud $\% 20$ autopercibida $\%$ $20 y \% 20$ acceso $\% 20 a \% 20$ salud $\% 20$ en $\% 20$ Chile.pdf?sequence=1\&isAllowed= $\mathrm{y}$

Carrasco, C. (2018). ¿Prevalece la dimensión económica en la integración de la persona migrante? La medición de la integración en el MIPEX?. Las Migraciones Euromediterráneas. Impacto Socioeconómico y Políticas, 900, 79-90.

Cea D’Ancona, María Ángeles; Valles Martínez, Miguel \& Eseverri Mayer, Cecilia. (2013). Inmigración. Filias y Fobias en Tiempos de Crisis. Madrid: Siglo XXI Editores.

Cogo, Denise; Gutiérrez, María; Huertas, Amparo (coords.). (2008). Migraciones transnacionales y medios de comunicación. Relatos desde Barcelona y Porto Alegre. Madrid: Catarata.

Cortés, G. (2009). Migraciones, construcciones transnacionales $y$ prácticas de circulación. Un enfoque desde el territorio. Párrafos Geográficos, 8(1), 35-53.Recuperado de:

http://www.igeopat.org/parrafosgeograficos/i mages/RevistasPG/2009_V8_1/11-2.df

De la Flor, I. (2013). La compleja vida de un migrante, su visión como derecho humano. Revista Jurídica de los Derechos Sociales. Lexsocial, 3(1), 96114. Recuperado de: https://www.upo.es/revistas/index.php/l ex_social/article/viewFile/403

Departamento de Extranjería y Migración. (2017). Reportes migratorios población migrante en Chile. Recuperado de: http://www.extranjeria.gob.cl/media/201 7/09/RM_PoblacionMigranteChile.pdf

Frías, C.; Galaz, C., \& Poblete, R. (2017). Políticas públicas y salud en materia de inmigración: Puntos críticos en la accesibilidad del sistema público chileno. Acciones e Investigaciones Sociales, 37, 61-93. Recuperado de: https://papiro.unizar.es/ojs/index.php/ai s/article/view/2188/1972

González-Vásquez, T.; Torres-Robles, C.; \& Pelcastre-Villafuerte, B. (2013) Utilización transnacional de servicios de salud por parte de los migrantes mexicanos en Estados Unidos. Salud Pública de México, 55(4), 477-484. Recuperado de: http://www.scielo.org.mx/scielo.php?scr ipt=sci_arttext\&pid=S003636342013001100006

Hernández, R.; Fernández, C. \& Baptista, P. (2014). Metodología de la Investigación. Sexta edición. México: Mcgraw-Hill / Interamericana Editores.

Hernández, P. (2013). Enfermedades infecciosas, migración y salud global. Estudio de caso: Bolivia. Revista de Investigación Educativa, 6(1), 111-126. Recuperado de: http://www.scielo.org.bo/scielo.php?scri pt=sci_arttext\&pid=S199740432013000100006

Hopenhayn, Martín \& Bello, Alvaro. (2001). Discriminación Étnico-racial y Xenofobia en América Latina y el Caribe. CEPAL, Serie Políticas Sociales, № 47, Santiago de Chile: CEPAL. Recuperado de: https://www.academia.edu/485611/Disc riminaci\%C3\%B3n_\%C3\%A9tnicoracial_y_xenofobia_en_Am\%C3\%A9ric a_Latina_y_el_Caribe

Instituto Nacional de Estadísticas - Chile. (2018). Síntesis de resultados censo 2017. Santiago de Chile: INE. Recuperado de: https://www.censo2017.cl/descargas/ho me/sintesis-de-resultadoscens02017.pdf

Lahoz, S. \& Forns, M. (2016). Discriminación percibida, afrontamiento y salud mental en migrantes peruanos en Santiago de Chile. Psicoperspectivas, 15(1), 157168. Recuperado de: http://www.psicoperspectivas.cl/index.p $\mathrm{hp} / \mathrm{psicoperspectivas/article/view/613}$ 
Levitt, P., \& Schiller, NG (2004). Conceptualización de la simultaneidad: una perspectiva del campo social transnacional en la sociedad. Revista de Migración Internacional, 38(3), 10021039. Recuperado de: https://www.research.manchester.ac.uk /portal/en/publications/conceptualizingsimultaneity-a-transnational-social-fieldperspective-on-society(8e465d9f-23274d54-87a3-594eafffa254).html

Liberona, N. (2015). Poder, contrapoder y relaciones de complicidad entre inmigrantes sudamericanos $y$ funcionarios del sistema público de salud chileno. Si Somos Americanos, Revista de Estudios Transfronterizo, $X V(2), \quad 15-40$. Recuperado de: https://www.researchgate.net/publicatio n/304235977_Poder_contrapoder_y_re laciones_de_complicidad_entre_inmigr antes_sudamericanos_y_funcionarios_ del_sistema_publico_de_salud_chileno

Márquez-Fernández, Á. \& Díaz, Z. (2005). Algunas consideraciones analíticas en torno al concepto de "sociedad civil" en Antonio Gramsci. Revista Venezolana de Ciencias Sociales, 9(1), 22-35. Recuperado de: https: //www.redalyc.org/pdf/309/30990103.p df

Ministerio de Salud. (2015). Salud del inmigrante. Santiago de Chile: MINSAL. Recuperado

de:

http://www.minsal.cl/salud-delinmigrante/

Ministerio de Salud. (2017). Política de salud de migrantes internacionales en Chile. Santiago de Chile: MINSAL. Recuperado de: http://redsalud.ssmso.cl/wpcontent/uploads/2018/01/Politica-deSalud-de-Migrantes-310-1750.pdf

Monge, S. \& Pérez-Molina, J. (2016). Infección por el VIH e inmigración. Enfermedades Infecciosas $y$ Microbiología Clínica. 34(7), 431-438. Recuperado de: https://dialnet.unirioja.es/servlet/articulo ?codigo $=6390410$
Organización Mundial de la Salud. (2003) «International Migration, Health andHuman Rights». Recuperado de: http://apps.who.int/iris/bitstream/handle/ 10665/42793/9241562536.pdf;jsessioni $d=B 63004 F 59 C C C F 2572 F E C E 200 D A$ D7D9D0? sequence $=1$

Organización Mundial de la Salud. (2004). Determinantes sociales de la salud. Recuperado de https://www.who.int/social_determinant s/es/

Organización Mundial de la Salud. (2005). ¿Qué es un sistema de salud?. Recuperado de: http://www.who.int/features/qa/28/es/

Organización Mundial de la Salud. (2018). Atención primaria de salud. Recuperado de:

http://www.who.int/topics/primary_healt h_care/es/

Organización Internacional para las Migraciones. (2010). Diálogo internacional sobre la migración taller intermedio relativo a migración $y$ transnacionalismo: oportunidades $y$ desafíos. Recuperado de: http://www.iom.int/jahia/webdav/shared/ shared/mainsite/microsites/IDM/worksh ops/migration_and_transnationalism_0 30910/background_paper_es.pdf

Organización Internacional para las Migraciones. (2015). Migrantes, refugiados en Europa superior a un millón en 2015, Informó la OIM. Recuperado de: https://www.iom.int/es/news/mas-deun-millon-de-migrantes-y-refugiadoshan-llegado-europa-en-2015-informola-oim.

Organización Internacional para las Migraciones. (2018). "¿Quién es un migrante?». Recuperado de: https://www.iom.int/es/quien-es-unmigrante.

Pavez, I. (2017). Integración sociocultural y derechos de las niñas y los niños migrantes en el contexto local. El caso de Recoleta (región Metropolitana, Chile). Chungará, Revista de 
Antropología Chilena, 49(4), 613- 622. Recuperado de: https: www.chungara.cl/Nols/2017/49-4/08PAVEZ-SOTO.pdf

Rocha, C.; Darsie, C.; Gama, A. y \& Dias, S. (2014). Experiencias en torno a la integración social y de la salud vividas por mujeres inmigrantes brasileñas y africanas en Portugal. Estudios Sociológicos XXXII, 94, 131-161. Recuperado de: https: www.redalyc.org/pdf/598/59840007006 .pdf

Santos, H.; Limón, N. \& Martínez, S. (2016). La atención de los migrantes centroamericanos en los servicios de salud en Tabasco, 2012-2014. Horizonte Sanitario, 15(3), 143-153. Recuperado de: www.revistas.ujat.mx/index.php/horizon te/article/view/1251/html

Stefoni, C. \& Bonhomme, M. (2014). Una vida en Chile y seguir siendo extranjeros. Si Somos Americanos, Revista de Estudios Transfronterizos, XIV(2), 81-101. Recuperado de: https://scielo.conicyt.cl/pdf/ssa/v14n2/ar t04.pdf

Solé, C.; Sordé, T.; Serradell, O; Alcalde, R.; Flecha, A.; Pettroff, A; Cavalcanti, L.; Parella, S.; Pávez, I.; Santamaría, E. \& Garzón. L. (2011). Cohesión social: aportaciones científicas y discursos políticos. Revista Internacional de Sociología, $\quad 69(1), \quad 9-32$. DOI:10.3989/ris.2009.09.14.

Recuperado

de: http://revintsociologia.revistas.csic.es/in dex.php/revintsociologia/article/view/36
6/373

Superintendencia de Salud (s.f). Garantías Explícitas en Salud (AUGE o GES). Santiago de Chile. Recuperado de: http://www.supersalud.gob.cl/difusion/6 65/w3-propertyvalue-1962.html

Torres, O. \& Garcés, A. (2013). Representaciones sociales de migrantes peruanos sobre su proceso de integración en la ciudad de Santiago de Chile. Polis, 12(35), 309-334. Recuperado de: www.academia.edu/4854593/Represen taciones_migrantes_peruanos_Santiag 0

Trummer, U.; Simonnot, N. \& Vanbiervliet, F. (2016). Access to health care for undocumented migrant children. european regulations and practices. DILEMATA, 8(21), 21-34. Recuperado de:

https://www.researchgate.net/publicatio n/303701422_Access_to_Health_Care _for_Undocumented_Migrant_Children _European_Regulations_and_Practices

Todos los trabajos publicados en Revista Salud \& Sociedad (ISSNe:0718-7475) están sujetos a una licencia Creative Commons Reconocimiento 4.0 Internacional

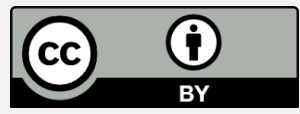




\section{RESUMO}

Antecedentes: 0 notório 0 aumento da população migrante no Chile nas três últimas décadas, motiva questionamentos a respeito do conhecimento científico sobre a atenção a saúde. Objetivo: Evidenciar a situação de pessoas migrantes no que se refere a atenção a saúde. Método: Realizamos uma revisão sistemática da literatura utilizando como base de dados: Redalyc, Dialnet e Scielo, com as palavras chaves: salud "and" migrantes; trabalhamos com vinte e um artigos de 2013 a 2018 , destes, dezesseis são estudos primários e cinco secundários; dez descrevem a situação de migrantes no Chile; onze relacionam 0 acesso a saúde dos migrantes com o poder, discriminação percebida, integração sócio-cultural, pobreza, políticas públicas, cobertura e utilização transnacional de serviços de saúde. Efetuamos uma análise de conteúdo, a partir das categorias migração e saúde, sistemas de saúde e acesso a atenção a saúde. Resultados: Em geral, a atenção a saúde costuma ser vivenciada em meio ao desconhecimento, falta de informação e discriminação, com barreiras de acesso. Conclusão: 0 anterior incide especialmente na qualidade de vida da população mogrante que vive em condições precárias, devido a escassa oferta de trabalho e de recursos econômicos, vulnerabilização de direitos, discriminação e esclusão social.

PALAVRAS-CHAVE: Emigração, imigração, sistema de saúde, discriminação social, exclusão social.

\section{RESUMEN}

Antecedentes: El notorio incremento de la población migrante hacia Chile en las tres últimas décadas, motiva interrogantes respecto a la necesidad de indagar en el conocimiento científico sobre la atención en salud. Objetivo: Evidenciar la situación de las personas migrantes en relación a la atención en salud en la literatura. Método: Realizamos una revisión sistematizada utilizando las bases de datos electrónicas: Redalyc, Dialnet y Scielo, con las palabras claves: salud "and" migrantes; trabajamos con veintiún artículos de 2013 a 2018, de éstos, dieciséis son estudios primarios y cinco secundarios; diez describen la situación de migrantes en Chile; once relacionan el acceso a la salud de los migrantes desde el poder, discriminación percibida, integración socio-cultural, pobreza, políticas públicas, cobertura y utilización transnacional de servicios de salud. Efectuamos análisis de contenido, a partir de las categorías migración y salud, sistemas de salud y acceso a la atención de salud. Resultados: En general, la atención de salud suele vivenciarse en medio de desconocimiento, falta de información y discriminación, como barreras de acceso. Conclusión: Lo anterior incide especialmente en la calidad de vida de la población migrante que vive en condiciones precarias, por escasa oferta laboral y de recursos económicos, vulneración de derechos, discriminación y exclusión social.

PALABRAS CLAVE: Emigración, inmigración, sistema de salud, discriminación social, exclusión social. 